\title{
Transfer of Type 1 (insulin-dependent) diabetes mellitus associated autoimmunity to mice with severe combined immunodeficiency (SCID)
}

\author{
J.S.Petersen ${ }^{1}$, M. O. Marshall ${ }^{2}$, S. Bakkeskov ${ }^{3}$, K. R.Hejnæs ${ }^{1}$, M.Høier-Madsen ${ }^{4}$, T. Dyrberg ${ }^{2}$ \\ ${ }^{1}$ Hagedorn Research Institute, Gentofte, Denmark \\ ${ }^{2}$ Novo Nordisk, Bagsværd, Denmark \\ ${ }^{3}$ Hormone Research Institute, University of California San Francisco, San Francisco, California, USA \\ ${ }^{4}$ The State Serum Institute, Copenhagen, Denmark
}

Summary. Pancreatic beta-cell destruction and development of Type 1 (insulin-dependent) diabetes mellitus are associated with circulating islet cell antibodies. Mice with severe combined immunodeficiency (SCID mice) were reconstituted with peripheral blood mononuclear cells from Type 1 diabetic patients, one who was antibody positive and one antibody negative, and from healthy individuals. Reconstituted mice were subsequently immunized with rat islets in incomplete Freunds adjuvant or adjuvant alone. Seventeen mice received peripheral blood mononuclear cells obtained at three different time points from the islet cell antibody positive patient. Before immunization with rat islets two mice developed antibodies to glutamic acid decarboxylase, a major target for antibodies in Type 1 diabetes, whereas none were positive for cytoplasmic islet cell antibodies. Following immunization with rat islets, glutamic acid decarboxylase antibodies were detected by immunoprecipitation in three additional mice, two of which also became positive for cyto- plasmic islet cell antibodies. Of 22 mice which received peripheral blood mononuclear cells from either the islet cell antibody negative patient $(n=5)$ or from two healthy individuals $(n=17)$, none were positive for islet cell autoantibodies before or after immunization. None of the islet cell antibody positive mice became hyperglycaemic, showed impaired glucose tolerance or islet cell damage when studied 40 days after immunization (i.e. 100 days after reconstitution). In conclusion these results show that human B lymphocytes producing diabetes-associated autoantibodies can be transferred to SCID mice and remain antigen sensitive, but also that autoantibodies alone are not sufficient to induce beta-cell destruction.

Key words: SCID mice, glutamic acid decarboxylase, islet cell antibodies, Type 1 (insulin-dependent) diabetes mellitus.
Type 1 (insulin-dependent) diabetes mellitus is the result of an autoimmune destruction of islet beta cells characterized by mononuclear cell infiltration of the islets of Langerhans and the presence of circulating islet cell autoantibodies [1-4]. Although several antigens have been implicated as targets for these autoantibodies, a $64 \mathrm{kDa}$ islet cell protein, recently identified as the enzyme glutamic acid decarboxylase (GAD) [5] seems to be a major target [6-8].

Detailed analysis of the immune responses associated with autoimmune diabetes in humans are not feasible and animal models, e.g. non-obese-diabetic mice and BB rats, have been used extensively to investigate the mechanisms of beta-cell destruction [9-12]. Although the diabetes in these animals appears to share homologies with Type 1 diabetes in man, it is not known whether the pathogenesis accurately reflects that in humans. Recently, it has been shown that mice with severe combined immunodeficiency (SCID) engrafted with human peripheral blood mononu- clear cells (PBMC) are permissive for long-term reconstitution of a partly functional human immune system [13]. Further, SCID mice engrafted with human embryonal thymus and lymph-node tissue have been shown to support the differentiation of human $\mathrm{T}$ and $\mathrm{B}$ cells following injections of human bone-marrow cells [14]. Based on these findings, several studies have shown that autoimmunity associated with different diseases, e.g. systemic lupus erythematosus, rheumatoid arthritis and thyroid disease, can be transferred to SCID mice with lymphocytes from affected patients [15-17].

In this study we show that SCID mice, reconstituted with PBMC from an islet cell antibody positive Type 1 diabetic patient, produce islet cell antibodies of human origin. Immunization of the reconstituted SCID mice with rat islets provoked the appearance of islet cell antibodies, indicating that the transplanted immune cells had, at least in part, preserved memory capability. Transfer of diabetes-associated autoimmunity into SCID mice may 
Table 1. Human autoantibodies in SCID mice reconstituted with peripheral blood mononuclear cells (PBMC) from Type 1 diabetic patients and healthy individuals

\begin{tabular}{llllll}
\hline $\begin{array}{l}\text { PBMC } \\
\text { donor/ } \\
\text { ICA status }\end{array}$ & $\begin{array}{l}\text { Immunization } \\
\text { of mice } \\
\text { with }(n)\end{array}$ & $\begin{array}{l}\text { GAD } \\
(n)\end{array}$ & $\begin{array}{l}\text { ICA } \\
(n)\end{array}$ & $\begin{array}{l}52 \mathrm{kDa} \\
(n)\end{array}$ & $\begin{array}{l}\text { ANA } \\
(n)\end{array}$ \\
\hline $\begin{array}{l}\text { Diabetic/ } \\
\text { negative }\end{array}$ & islets (2) & 0 & 0 & 0 & 0 \\
IFA (3) & 0 & 0 & 0 & 0 \\
posiabetic/ & islets(10) & 3 & 2 & $1 / 3$ & 1 \\
Control/ & IFA (7) & 2 & 0 & $0 / 2$ & 1 \\
negative & IFlets (3) & 0 & 0 & 0 & 0 \\
Control/ & islets (6) & 0 & 0 & 0 & 0 \\
negative & IFA (6) & 0 & 0 & 0 & 0 \\
\hline
\end{tabular}

SCID mice were reconstituted with PBMC from a glutamic acid decarboxylase (GAD) and islet cell antibody (ICA)-positive patient isolated $4(n=5), 10(n=5)$ and $18(n=7)$ months after onset of disease and with PBMC from an GAD- and ICA-negative patient isolated 4 months after onset. In addition healthy individuals who were also GAD- and ICA-negative were used as control subjects. All sera were tested for GAD, ICA and anti-nuclear antibodies (ANA), the number of positive mice is indicated for each group. The number of mice reacting with the $52 \mathrm{kDa}$ antigen in immunoblotting analysis is indicated as positive out of total number tested. Mice were immunized with rat islets in incomplete Freunds adjuvant (islets) or incomplete Freunds adjuvant alone (IFA)

allow a more precise analysis of the mechanisms involved in the pathogenesis of autoimmunity.

\section{Subjects, materials and methods}

\section{SCID mice and immunization}

C.B-17 scid/scid (SCID) mice, (Bomholtgaard, Ry, Denmark; male, 5-6 weeks old), with no endogenous immunoglobulin production $\left(<10 \mathrm{ng} / \mathrm{ml}\right.$ mouse $\mathrm{IgG}$ in serum), were injected i. p. with $20 \times 10^{6} \mathrm{Fi}-$ coll-isolated PBMC per mouse. The PBMC were obtained from Type 1 diabetic patients, one islet cell cytoplasmic antibody (ICA) and GAD antibody negative, and one ICA and GAD antibody positive (Table 1). The PBMC and serum from the antibody-positive patient were obtained 4 months, 10 months and 18 months after clinical onset. SCID mice were also reconstituted with PBMC from two healthy individuals (Table 1 ). Sixty days after reconstitution with PBMC, mice were immunized i.p. with either neonatal Wistar rat islets (1000 islets/mouse) in incomplete Freunds adjuvant (IFA) or IFA alone. Blood samples were obtained one day before and 19 days after immunization. The mice were analysed every 2 weeks for elevated blood glucose levels and 19 days after immunization for impaired glucose tolerance. Blood samples were collected before glucose injection and after glucose injection i. p. ( $2 \mathrm{~g} / \mathrm{kg}$ body weight) at $20,40,60,90$ and $120 \mathrm{~min}$.

Frozen sections of the reconstituted SCID mice pancreata ( $3 \mu \mathrm{m}$ thick, acetone fixed) were analysed for islet cell pathology 100 days after reconstitution, i. e. 40 days after immunization. The same sections were also analysed for the presence of human lymphocytes or immunoglobulins by immunohistochemistry using fluorescence conjugated monoclonal antibodies to human $T$ cells (CD3, fluorescein isothiocyanate (FITC) conjugated; Immunotech, Marseille, France), human B cells (CD19, phycoerythrin-conjugated, Immunotech) or to human Ig (goat-anti-human IgG H L , FITC-conjugated; Zymed, South San Francisco, Calif., USA). After incubation for $1 \mathrm{~h}$ with antibodies, the sections were washed in Dulbecco's phosphate buffered saline (PBS) (Gibco, Paisley, UK) and analysed in a fluorescence microscope.

\section{Assays for human immunoglobulins}

Human IgG and IgM concentrations in serum were determined by an antibody capture ELISA assay. Microtitreplates, coated with goat-anti-human IgG or IgM (Zymed; $5 \mu \mathrm{g} / \mathrm{ml}$ in $50 \mathrm{mmol} / \mathrm{l}$ $\mathrm{Na}_{2} \mathrm{CO}_{3} / \mathrm{NaHCO}_{3}$-buffer) were washed $(3 \times$ in $\mathrm{PBS}$ with $0.1 \%$ Tween 20), and incubated with serial dilutions (in PBS containing $1 \%$ BSA and $0.1 \%$ Tween 20 ) of the test samples for $2 \mathrm{~h}$. Bound Ig was quantified with peroxidase-conjugated goat-anti-human IgG (Zymed) (substrate: $0.4 \mathrm{mg} / \mathrm{ml} \mathrm{O}$-phenyldiamine and $0.03 \%$ hydrogen peroxide in water). The lower detection limit of the $\operatorname{IgG}$ assay was $10 \mathrm{ng} / \mathrm{ml}$. There was no detectable cross-reaction to mouse Ig in this assay.

\section{Autoantibody detection}

To detect cytoplasmic ICA, frozen sections of human pancreas ( $4 \mu \mathrm{m}$ thick, blood group 0 , acetone-fixed) were incubated with sera for $90 \mathrm{~min}$ (mouse sera were not diluted) and washed in PBS. Bound immunoglobulins were visualized with peroxidase-conjugated Protein A (Amersham Int., Amersham, Bucks., UK) and substrate $1 \mathrm{mg} / \mathrm{ml}$ diaminobenzidine, $0.023 \% \mathrm{H}_{2} \mathrm{O}_{2}$ or FITC-conjugated rabbit-anti-human $\operatorname{IgG}$ (Dakopatts, Copenhagen, Denmark).

For immunoprecipitation analysis of islet cell antigens, Tx-114 detergent phase purified cytosolic fractions of ${ }^{35} \mathrm{~S}$-methionine-labelled neonatal rat islets were immunoprecipitated as previously described [5]. Briefly, a cytosolic fraction, prepared from neonatal rat islets, was subjected to temperature-induced Tx-114 phase separation [5]. Aliquots of the detergent phase containing amphiphilic soluble proteins were incubated overnight with sera to form immunocomplexes. The immunocomplexes were isolated by adsorption to Protein A-Sepharose. The immunoprecipitates were analysed by SDS-PAGE (10\%) under reducing conditions followed by fluorography [5].

For immunoblotting, neonatal rat islets were solubilized by boiling for $3 \mathrm{~min}$ in $90 \mathrm{mmol} / 1$ Tris $\mathrm{HCl}, 17 \%$ sucrose, $3 \% \mathrm{SDS}$, and $10 \mathrm{mmol} / \mathrm{l}$ dithiothreitol. Approximately $1 \times 10^{4}$ islets per $10 \mathrm{~cm}$ of gel were subjected to $10 \%$ SDS-PAGE, electroblotted onto nitrocellulose filters and immunostained as previously described [18]. Bound $\mathrm{Ig}$ was visualized with goat-anti-human or goat anti-mouse $\mathrm{F}\left(\mathrm{ab}_{2}\right) \mathrm{IgG}$, conjugated to alkaline-phosphatase (Zymed), and a chromogenic substrate. All SCID mouse sera were used in a 1:5 dilution. Human sera were used in a 1: 50 dilution.

The presence of anti-nuclear antibodies (ANA) was determined using HEp-2 slides (Immuno-concepts; Sacramento, Calif., USA), and the indirect immunofluorescence assay [19] was performed using FITC-conjugated anti-human IgG (Dakopatts).

\section{Results}

Reconstituted SCID mice produce human immunoglobulins. All reconstituted SCID mice produced human immunoglobulins, but in highly variable concentrations (serum huIgG $1-2816 \mu \mathrm{g} / \mathrm{ml}$, huIgM $0-344 \mu \mathrm{g} / \mathrm{ml}$ ), reaching peak levels 8-11 weeks after injection of PBMC. To detect beta-cell reactive autoantibodies, the mouse sera were tested by immunohistochemistry, immunoprecipitation, and immunoblotting analysis.

Antibodies in SCID mice reconstituted with PBMC from an ICA-positive Type 1 diabetic patient. Seventeen SCID mice were reconstituted with PBMC from the ICA-positive patient which had been obtained $4(n=5), 10(n=5)$ and $18(n=7)$ months after clinical onset (Table 1$)$. The mice were analysed for ICA production before and after immunization with rat islets $(n=10)$ or injection with IFA 


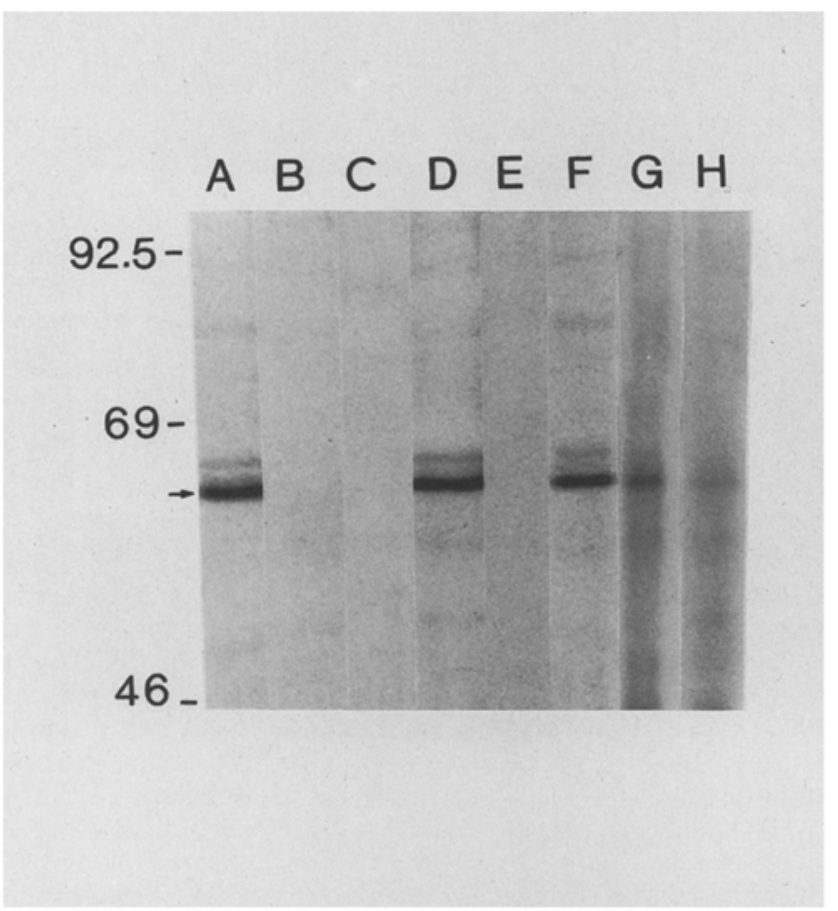

Fig. 1. Glutamicacid decarboxylase (GAD) autoantibodies in SCID mice reconstituted with peripheral blood mononuclear cells (PBMC) were tested in immunoprecipitation analysis using neonatal rat islets. Lane A: Monoclonal antibody to GAD (GAD6) [24]. B: Serum from a healthy control subject (serum huIgG $7050 \mu \mathrm{g} / \mathrm{ml}$ ). C: Serum from a SCID mouse reconstituted with PBMC from the control in lane B (serum hulgG $575 \mu \mathrm{g} / \mathrm{ml}$ ). D: Serum from an islet cell antibody positive Type 1 diabetic patient (serum huIgG $6016 \mu \mathrm{g} / \mathrm{ml}$ ). Serum from a SCID mouse reconstituted with PBMC from the patient in lane D: $\mathrm{E}: 60$ days after reconstitution but before immunization (serum huIgG $216 \mu \mathrm{g} / \mathrm{ml}$ ). F: 19 days after immunization with rat islets (serum huIgG $518 \mu \mathrm{g} / \mathrm{ml}$ ). Serum from a another SCID mouse reconstituted with $\mathrm{PBMC}$ from the patient in lane $\mathrm{D}: \mathrm{G}$ : 60 days after reconstitution (serum hulgG $401 \mu \mathrm{g} / \mathrm{ml}$ ). H: 19 days after injection with incomplete Freunds adjuvant only (serum huIgG $416 \mu \mathrm{g} / \mathrm{ml})$. The arrow indicates the location of the GAD protein

alone $(n=7)$ on day 60 . Before immunization all 17 reconstituted mice were negative for cytoplasmic ICA measured by indirect immunofluorescence on frozen human pancreatic sections. In contrast two of the reconstituted mice were positive for GAD antibodies by immunoprecipitation analysis prior to antigen stimulation or IFA injection (one in each group from SCID mice reconstituted with PBMC obtained 4 and 18 months after clinical onset). Immunization of one of the GAD antibody positive mice with rat islets did not enhance the immunoreactivity towards GAD (not shown). The other GAD antibody-positive mouse was treated with IFA only (Fig. 1). The immunoreactivity of GAD antibodies in mice, which were positive before immunization, was significantly lower than for antibodies induced by immunization with rat islets (see below, Fig. 1).

Immunization of reconstituted mice with rat islets resulted in the development of GAD antibodies in an additional three mice ( $n=1$ and $n=2$ from SCID mice reconstituted with PBMC obtained 4 and 10 months after clinical onset, respectively) (Fig. 1), two of which were also positive for cytoplasmic ICA by the indirect immunofluorescence assay on both human (Fig. 2) and SCID mouse pancreas (not shown). Injection of IFA alone did not induce ICA. The immunoreactivity of GAD antibodies induced in reconstituted mice by immunization was comparable to that of the GAD antibodies in the serum from the donor patient despite a much higher $\mathrm{IgG}$ concentration in the patient serum (IgG: $8064 \mu \mathrm{g} / \mathrm{ml}$ in the patient compared to $512 \mu \mathrm{g} / \mathrm{ml}, 355 \mu \mathrm{g} / \mathrm{ml}$ and $518 \mu \mathrm{g} / \mathrm{ml}$ in the three SCID mice, respectively). This suggests that GAD antibody producing B cells were selectively enhanced in the reconstituted SCID mice.

In immunoblotting analysis of total lysates from rat islets, a $52 \mathrm{kDa}$ molecule was recognized by the ICA-positive, but not the antibody-negative patient serum (Fig. 3). Sera from SCID mice reconstituted with the PBMC from the ICA-negative $(n=5)$ and the ICA-positive patients $(n=5)$ (Table 1) were also tested by immunoblotting. Serum from one of the ICA- and GAD-positive SCID mice, obtained after immunization with rat islets, also recognized the $52 \mathrm{kDa}$ antigen. The antibodies were only present after immunization, whereas serum obtained from the same mouse the day before immunization did not bind the antigen (Fig. 3). In the post-immune serum from this

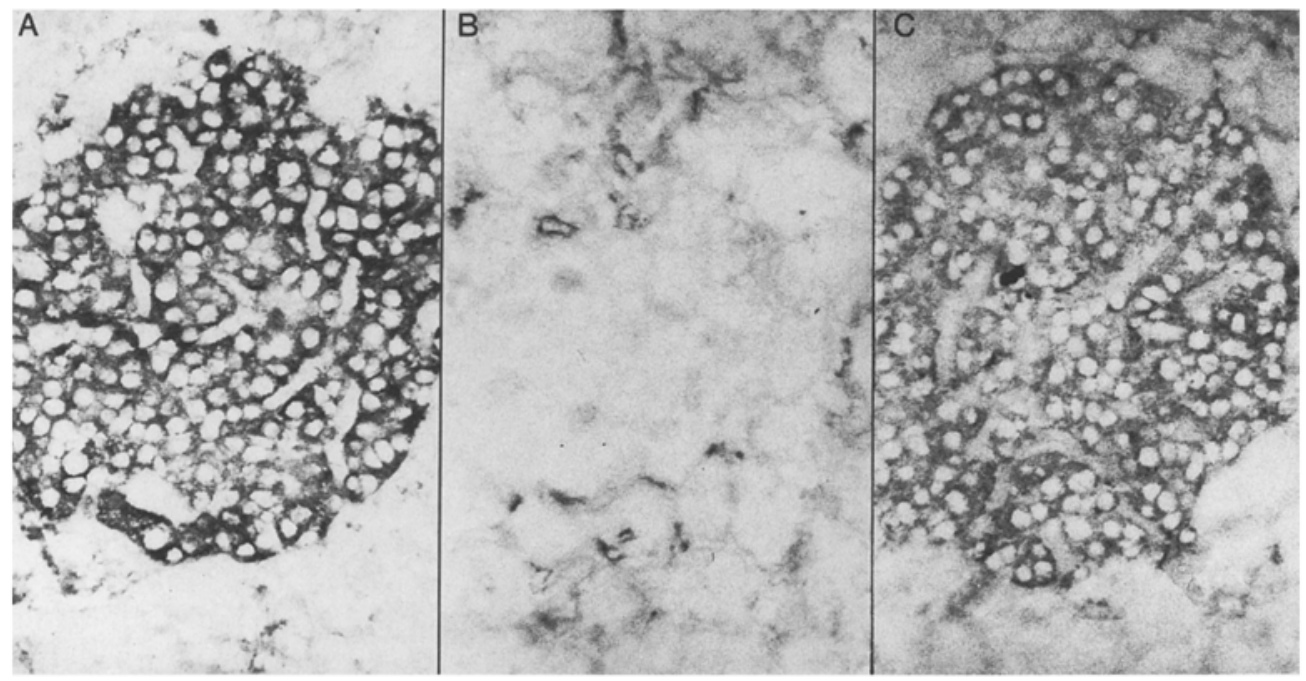

Fig. 2 A-C. To detect islet cell cytoplasmic antibodies, frozen sections of human pancreas were stained with serum from a Type 1 diabetic patient and from a SCID mouse reconstituted with peripheral blood mononuclear cells from the same patient before and after immunization with rat islets A: Patient serum (serum huIgG $7823 \mu \mathrm{g} / \mathrm{ml}$ ) at a dilution of $1: 64$ B: Serum from the SCID mouse, obtained 60 days after reconstitution but before immunization, undiluted (serum huIgG $221 \mu \mathrm{g} / \mathrm{ml}$ ) C: Serum from the SCID mouse in B, obtained 19 days after immunization, undiluted (huIgG $512 \mu \mathrm{g} / \mathrm{ml}$ ) 


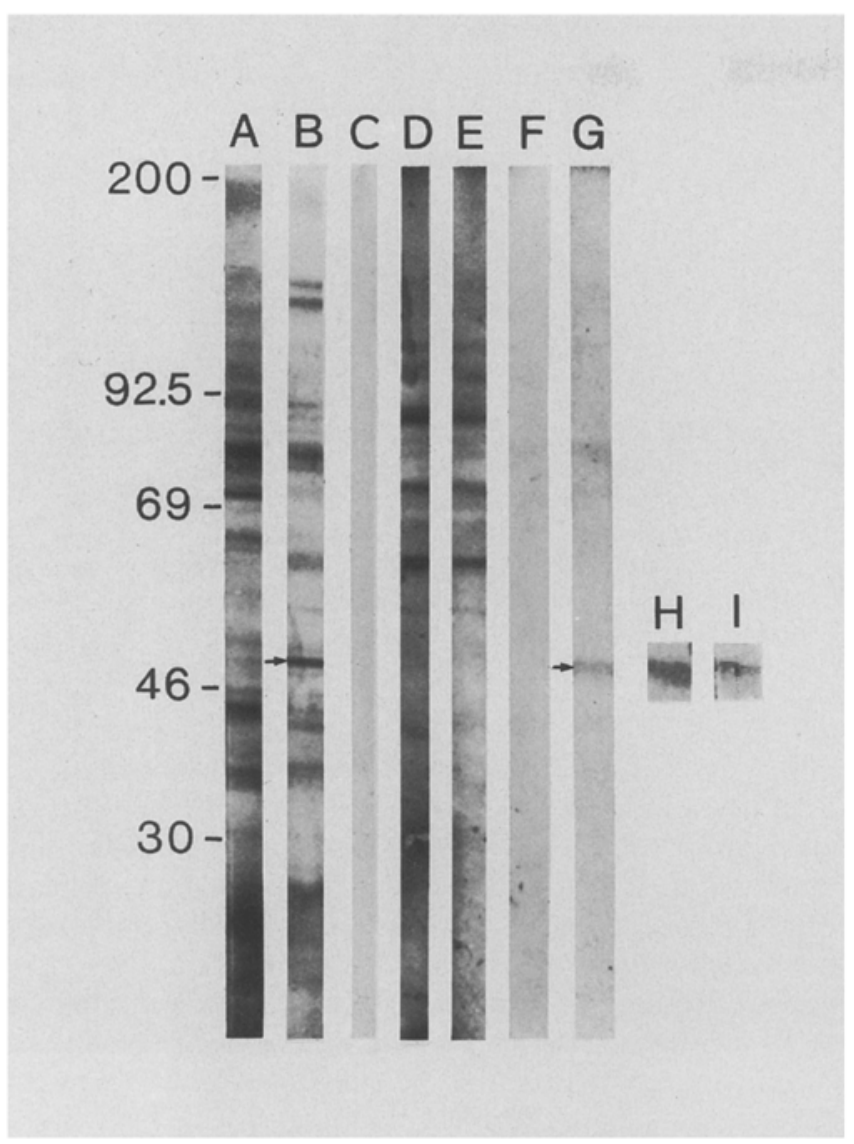

Fig.3. Western blot analysis of total lysates of neonatal rat islets using sera from Type 1 diabetic patients and from SCID mice reconstituted with peripheral blood mononuclear cells (PBMC). A: Serum from an islet cell antibody (ICA) negative Type 1 diabetic patient (serum huIgG $14400 \mu \mathrm{g} / \mathrm{ml}$ ). B: Serum from an ICA-positive Type 1 diabetic patient (serum huIgG $7823 \mu \mathrm{g} / \mathrm{ml}$ ). C: Serum from a non-reconstituted, control SCID mouse. Serum from a GAD- and ICA-negative SCID mouse reconstituted with PBMC from the ICA-positive patient in lane B: D: 60 days after reconstitution but before immunization (serum huIgG $896 \mu \mathrm{g} / \mathrm{ml}$ ). E: 19 days after immunization with rat islets (serum huIgG $2816 \mu \mathrm{g} / \mathrm{ml}$ ). Serum from an ICA- and GAD-positive SCID mouse reconstituted with PBMC from the patient in lane B: F: 60 days after reconstitution but before immunization (serum huIg $221 \mu \mathrm{g} / \mathrm{ml}$ ). G: 19 days after immunization with rat islets (serum huIgG $512 \mu \mathrm{g} / \mathrm{ml}$ ). H: The same serum as in lane $\mathrm{G}$ pre-incubated for $1 \mathrm{~h}$ with a lysate of Epstein-Barr-virus transformed lymphocytes $\left(3 \times 10^{6}\right.$ cells $)$. : The same serum as in lane $\mathrm{G}$ pre-incubated for $1 \mathrm{~h}$ with a lysate of neonatal rat islets (1000 islets, approximately $1-1.5 \times 10^{6}$ beta cells). The arrow indicates the location of the $52 \mathrm{kDa}$ protein

SCID mouse, pre-incubation with rat islets, but not human lymphocytes, reduced the binding to the $52 \mathrm{kDa}$ antigen (Fig. 3), indicating that it is not a common cellular determinant. There was no binding to the GAD molecules on the immunoblots with any of the patient or SCID mice sera tested, despite their binding to the antigen in immunoprecipitation analysis. This is consistent with the finding that antibodies to GAD in diabetic patients are directed to configurational and not primary epitopes in the molecule.

Antibodies in mice reconstituted with PBMC from ICAnegative individuals. None of the mice reconstituted with
PBMC from the ICA-negative patient were found to be ICA or GAD positive regardless of immunization with rat islets in IFA $(n=2)$ or IFA alone $(n=3)$ (Table 1$)$.

Islet cell antibodies could not be detected in any of the mice reconstituted with PBMC from the two healthy control subjects, either after immunization with islet cells $(n=9)$ in IFA or IFA alone $(n=8)$ (Table 1$)$.

Neither control SCID mice, which had not been reconstituted with PBMC nor mice from other strains (agematched males), were ICA positive or could precipitate the GAD islet cell antigen (data not shown).

Anti-nuclear-antibodies in mice reconstituted with $P B M C$. Sera from two SCID mice reconstituted with PBMC from the ICA-antibody positive patient, obtained 19 days after immunization, were found to be positive for anti-nuclearantibodies (ANA) during analysis for ICA (one had been immunized with islets and one with IFA alone). These sera induced a peripheral staining of the nuclei of endocrine as well as exocrine cells on sections of human pancreas (Fig. 4). This staining pattern is normally seen with antibodies to double-stranded DNA or histones [13]. The results were confirmed by staining of HEp-2 cells, where one of the ANA-positive sera showed a homogeneous pattern with mitotic cells showing fluorescence of the chromosome region. Serum from the patient was not ANA-positive at any time, i.e. at 4, 10 and 18 months after onset (Fig. 4).

Histologic and metabolic analysis of mice reconstituted with PBMC. None of the reconstituted SCID mice showed elevated blood glucose levels, either fasting or non-fasting (range $4-10 \mathrm{mmol} / \mathrm{l}$, mean $6.5 \mathrm{mmol} / 1$ ) at any time, or impaired glucose tolerance after immunization with rat islets. Histological examination of the pancreata from the reconstituted SCID mice, 40 days after immunization with either rat islets or IFA alone, revealed no islet damage or insulitis. No human T cells (CD3), B cells (CD21) or human immunoglobulins were detected in the islets.

\section{Discussion}

In this study we show that SCID mice reconstituted with PBMC from Type 1 diabetic patients can produce autoantibodies against diabetes-associated antigens. Recently, it has been demonstrated that athymic CD-1 nu/nu mice injected with PBMC from newly-diagnosed Type 1 diabetic patients develop insulitis and beta-cell damage [20]. In contrast, we did not observe insulitis or beta-cell damage in the reconstituted SCID mice, but studies using PBMC from additional Type 1 diabetic patients are required to compare these results to those reported with the athymic mice.

Previously, SCID mice reconstituted with PBMC from patients with Graves' disease characterized by high titres of thyroid autoantibodies, developed autoantibodies to thyroid peroxidase (TPO) [17]. Immunization with TPO did not induce autoantibodies in reconstituted SCID mice initially negative for anti-TPO. In contrast, our results 

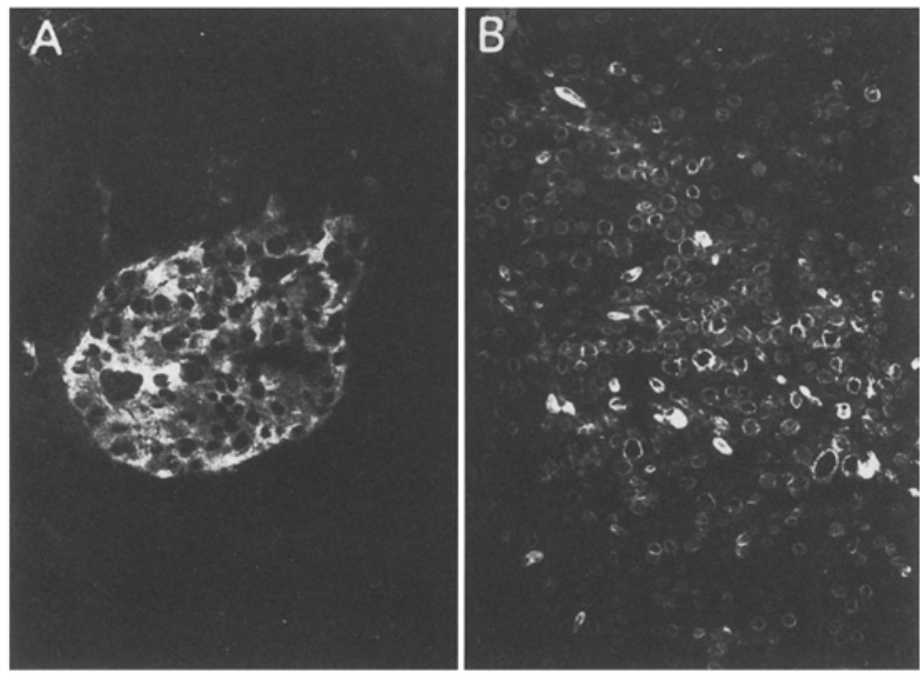

Fig.4A,B. Anti-nuclear antibodies (ANA) were detected on frozen sections of human pancreas

A: Serum from a Type 1 diabetic patient which is ANA negative, (serum hulgG $8064 \mu \mathrm{g} / \mathrm{ml}$ ), undiluted

B: ANA-positive serum from a SCID mouse reconstituted with peripheral blood mononuclear cells from the patient in $\mathbf{A}$, obtained 60 days after reconstitution, (serum huIgG $486 \mu \mathrm{g} / \mathrm{ml}$ ), undiluted

suggest the possibility that a preferential proliferation/activation of autoreactive B-cell clones transferred into SCID mice can be achieved by active immunization, since immunization of reconstituted SCID mice with rat islets induced the production of diabetes-associated autoantibodies. Interestingly, the ${ }^{35} \mathrm{~S}$-methionine-labelled GAD immunoprecipitated by the patient serum was comparable in intensity to that precipitated with sera from the immunized, antibody-positive SCID mice, despite the approximately 15 times lower huIgG concentration in the mice. Although fluorographs of ${ }^{35} \mathrm{~S}$-methionine-labelled material are only semiquantitative, the data strongly suggest that the relative concentration of GAD antibodies is significantly higher in the mice than in the patient. We therefore attempted to isolate islet specific B-cell clones from the reconstituted SCID mice. Several human $\operatorname{IgG}$ producing Epstein-Barr virus transformed B-cell clones (CD21, huIgG and HLA-DQ positive and mouse IgG negative in FACS analysis) were generated from the spleen of one of these SCID mice; however, none produced ICA or GAD antibodies (data not shown).

ICA measured by indirect immunofluorescence on frozen sections of human pancreas are likely to be directed to the GAD molecule and perhaps additional molecules. GAD antibodies were detected in five reconstituted SCID mice including two which were positive before immunization with rat islets. In contrast, ICA were only detected in two of those mice and only following immunization. This result is in agreement with studies in prediabetic individuals where GAD antibodies are sometimes detected before, but never later than ICA [6]. Recently, autoantibodies to a $52 \mathrm{kDa}$ islet cell antigen were detected in sera from Type 1 diabetic patients and NOD mice by immunoblotting analysis [21]. This may be the same antigen as the one recognized by the serum of one of the diabetic patients in an ICA-positive SCID mouse. Taken together, these data indicate that the $52 \mathrm{kDa}$ islet cell antigen may be another autoantigen of interest in Type 1 diabetes.

The significance of autoantibodies in the pathogenesis of Type 1 diabetes [1] has been difficult to access. In the present study, none of the islet cell antibody positive SCID mice developed abnormal glucose levels or insulitis, at least not during an observation period of 60 days following reconstitution and additional 40 days following immunization. Two hypotheses can be suggested to explain this. First, ICA and GAD antibodies by themselves are not sufficient to induce beta-cell destruction, but rather appear as a secondary phenomena to an autoimmune attack on the beta cell. This would be in agreement with results in animal models of Type 1 diabetes, where beta-cell destruction seems to be T-cell and not B-cell mediated [22]. Alternatively human antibodies may play a role in beta-cell damage, but are unable to do so in the mouse, either because mouse complement fails to bind human IgG efficiently, or because the antibodies are unable to bind to their target antigen in SCID mouse islets due to low expression or sequence differences. However, although mouse islets express significantly lower levels of GAD than both rat and human islets (unpublished results, J.S.Petersen et al.) serum from the ICA-positive diabetic patient was able to stain islets in frozen sections of human, monkey, rat and SCID mouse pancreas (not shown).

The observation that sera from two reconstituted SCID mice contained ANA was surprising since the donor was negative for ANA. However, this supports a previous observation where SCID mice, reconstituted with synovial cells from patients with rheumatoid arthritis, produced both IgM rheumatoid factor and ANA, although the donor patient serum was negative for ANA [16]. These results are difficult to explain, but perhaps the autoantibody-producing B cells are resting in the donor, and first induced to produce autoantibodies following transfer to the SCID mice, either due to lack of suppression or exposure to cross-reacting mouse antigens. Alternatively, the generation of ANA might be the result of unmasking low levels of ANA present in healthy subjects.

In conclusion, our findings suggest that reconstituted SCID mice may be useful in investigations of autoimmunity in Type 1 diabetes and elucidation of the pathogenic mechanisms. Furthermore, reconstituted SCID mice could prove useful in obtaining human monoclonal autoantibodies [23], against antigens not yet isolated and characterized. 
Acknowledgements. We are indebted to Ms. E. Jost Jensen and Ms. A. Andersen for expert technical assistance and Dr. K. Nørgård, Steno Diabetes Center, Gentofte (Denmark) for supplying blood from diabetic patients. J.S.Petersen was supported by the Danish Research Academy and S.Bækkeskov by NIH-grant no. 1P01 DK41822-01.

\section{References}

1. Lernmark $\AA$ (1985) Molecular biology of type 1 (insulin-dependent) diabetes mellitus. Diabetologia 28: 195-203

2. Maclaren N, Schatz D, Drash A, Grave G (1989) The initial pathogenic events in insulin-dependent diabetes. Diabetes 38: $534-$ 538

3. Eisenbarth GS (1986) Type 1 diabetes mellitus. A chronic autoimmune disease. New Engl J Med 314: 1360-1368

4. Gepts W (1965) Pathologic anatomy of the pancreas in juvenile diabetes mellitus. Diabetes 14: 619-633

5. Bakkeskov S, Aanstoot HJ, Christgau S et al. (1990) Identification of the $64 \mathrm{k}$ autoantigen in insulin-dependent diabetes as the GABA-synthesizing enzyme glutamic acid decarboxylase. Nature (Lond) 347: 151-156

6. Bækkeskov S, Nielsen $\mathrm{JH}$, Marner B, Bilde T, Ludvigsson J, Lernmark $\AA$ (1982) Autoantibodies in newly diagnosed diabetic children immunoprecipitate human pancreatic islet cell proteins. Nature (Lond) 298: 167-169

7. Bækkeskov S, Landin M, Kvist J et al. (1987) Antibodies to a $M_{r}$ 64000 human islet cell antigen precede the clinical onset of insulin dependent diabetes. J Clin Invest 79:926-934

8. Atkinson MR, Maciaren NK, Scharp DW, Lacy PE, Riley WJ (1990) $64000 \mathrm{M}_{\mathrm{r}}$ autoantibodies as predictors of insulin-dependent diabetes. Lancet 335: 1357-1360

9. Rossini AA, Greiner DL, Friedman HP, Mordes JP (1993) Immunopathogenesis of diabetes mellitus. Diabetes Rev 1: 43-75

10. Scott J (1990) The spontaneously diabetic BB rat: sites of the defects leading to autoimmunity and diabetes mellitus. Curr Top Microbiol Immunol 156:1-14

11. Hanafusa T, Tarui S (1990) Immune pathogenesis of diabetes in the nonobese diabetic mouse. Curr Top Microbiol Immunol 156: $15-26$

12. Lampeter EF, Signore A, Gale EAM, Pozzilli P (1989) Lessons from the NOD mouse for the pathogenesis and immunotherapy of human type 1 (insulin-dependent) diabetes mellitus. Diabetologia 32: 703-708

13. Mosier DE, Gulizia RJ, Baird MS, Wilson DB (1988) Transfer of a functional human immune system to mice with severe combined immunodeficiency. Nature (Lond) 335: 256-258
14. McCune JM, Namikawa R, Kaneshima H, Shultz LD, Liberman M, Weissman IL (1988) The SCID-hu mouse: murine model for the analysis of human hematolymphoid differentiation and function. Science 241: 1632-1639

15. Duchosal MA, McConahey PJ, Robinson CA, Dixon FJ (1990) Transfer of human systemic lupus erythematosus in severe combined immunodeficient (SCID) mice. J Exp Med 172:985-988

16. Tighe H, Silverman GJ, Kozin F et al. (1990) Autoantibody production by severe combined immunodeficient mice reconstituted with synovial cells from rheumatoid arthritis patients. Eur J Immunol 20: 1843-1848

17. Davies TF, Kimura H, Fong P et al. (1991) The SCID-hu mouse and thyroid autoimmunity - characterization of human thyroid autoantibody secretion. Clin Immunol Immunolpathol 60: 319 330

18. Atar D, Dyrberg T, Michelsen B et al. (1989) Site-specific antibodies distinguish single amino acid substitutions in position 57 in HLA-DQ b-chain alleles associated with insulin-dependent diabetes. J Immunol 143: 533-537

19. Humbel R, Kadusch P (1985) Chemical fixation of proteins. In: Peeters H (ed) Protides of the biological fluids. Pergamon Press, Oxford, pp. 385-389

20. Calcinaro F, Hao L, Chase HP et al. (1992) Detection of cellmediated immunity in type I diabetes mellitus. J Autoimmunity 5: $137-147$

21. Karounos DK, Thomas JW (1990) Recognition of common islet antigen by autoantibodies from NOD mice and humans with IDDM. Diabetes 39: 1085-1090

22. Cooke A (1990) An overview on possible mechanisms of destruction of the insulin-producing beta cell. Curr Top Microbiol Immunol 164: 125-142

23. Duchosal MA, Eming AS, Fischer $P$ et al. (1992) Immunization of hu-PBL-SCID mice and the rescue of human monoclonal Fab fragments through combinatorial libraries. Nature (Lond) 355: 258-262

24. Chang YC, Gottlieb DI (1988) Characterization of the proteins purified with monoclonal antibodies to glutamic acid decarboxylase. J Neurosci 8:2123-2130

Received: 30 November 1992

and in revised form: 19 February 1993

Dr. T.Dyrberg

Novo Nordisk

Novo Allé

DK-2880 Bagsvaerd

Denmark 